\title{
LA-UR-21-23989
}

Approved for public release; distribution is unlimited.

Title: $\quad$ Protocols for Uranium Carbon Analysis

Author(s): $\quad$ Tubesing, Philip K.

Korzekwa, Deniece Rochelle

Bremser, Julie K

Intended for: Report

Issued: 
Disclaimer:

Los Alamos National Laboratory, an affirmative action/equal opportunity employer, is operated by Triad National Security, LLC for the National Nuclear Security Administration of U.S. Department of Energy under contract 89233218CNA000001. By approving this article, the publisher recognizes that the U.S. Government retains nonexclusive, royalty-free license to publish or reproduce the published form of this contribution, or to allow others to do so, for U.S. Government purposes. Los Alamos National Laboratory requests that the publisher identify this article as work performed under the auspices of the U.S. Department of Energy. Los Alamos National Laboratory strongly supports academic freedom and a researcher's right to publish; as an institution, however, the Laboratory does not endorse the viewpoint of a publication or guarantee its technical correctness. 


\section{Protocols for Uranium Carbon Analysis}

Philip K. Tubesing, Deniece R. Korzekwa, Julie K. Bremser

Los Alamos National Laboratory, Sigma Complex

In 1998, MST-6 (now SIGMA) installed a Horiba EMIA-8200 Carbon/Sulfur analyzer to provide the ability to perform in-house chemical analysis on a variety of materials including uranium. While many of the results and procedures were detailed in program files, no compiled record of the overall analytic process was ever published. This retrospective utilizes existing logbooks, operator interviews, instrument manuals, and notes to catalog what is known about the past procedures and protocols for carbon analysis that were established and present the data informing those decisions.

\section{Table of Contents}

Established Protocols for Carbon Analysis ...........................................................2

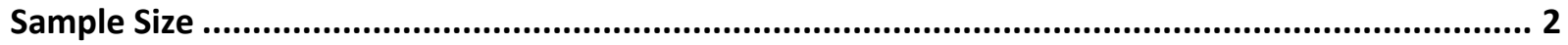

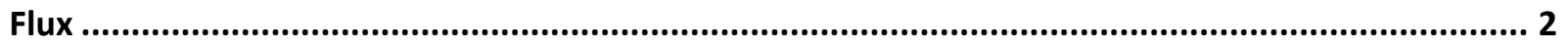

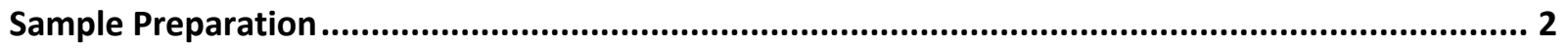

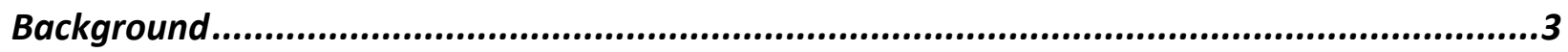

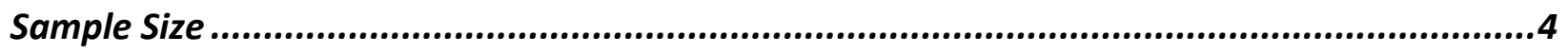

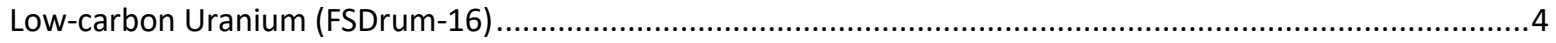

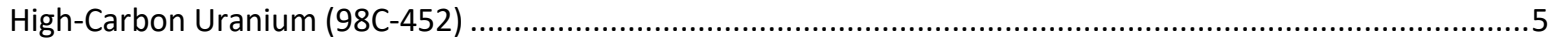

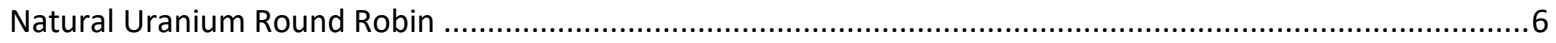

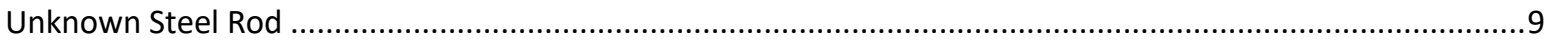

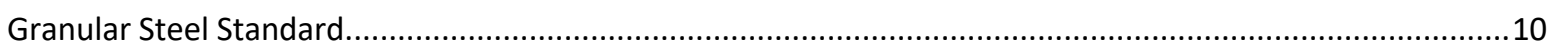

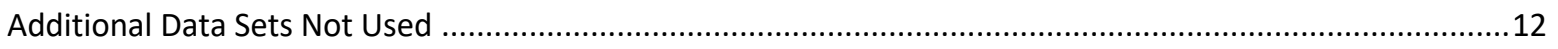

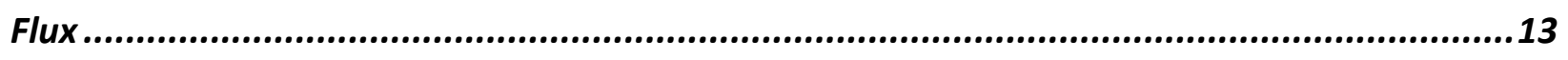

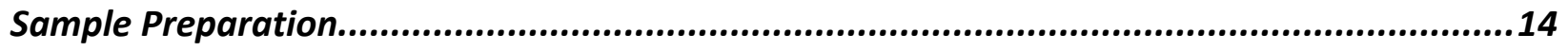

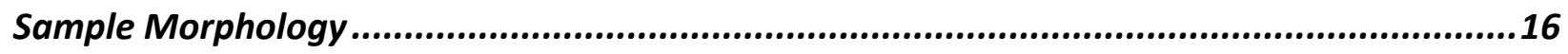




\section{Established Protocols for Carbon Analysis}

\section{Sample Size}

- We established $\underline{1 g}$ as the standard sample size for solid, monolithic samples of uranium and most other materials, based upon manufacturer's recommendations and several sample size studies.

- We established $0.5 \mathrm{~g}(500 \mathrm{mg})$ as the minimum sample size we felt provided consistent results, based upon several sample size studies.

Flux

- We established the following flux recipe standard based upon the manufacturer's operating manual and some experimental testing.

$1.5 \mathrm{~g} \mathrm{~W}$ (tungsten) + 0.3g Sn (tin) + sample

\section{Sample Preparation}

- We established the following sample preparation method based upon manufacturer's recommendations, experience at other facilities performing uranium carbon analysis, and our own evaluation tests.

\begin{tabular}{|l|l|}
\hline 1. Ultrasonic bath in soapy water & $60 \mathrm{sec}$ \\
\hline 2. $10 \%$ dilute nitric acid & $90 \mathrm{sec}$ \\
\hline 3. De-ionized water rinse & $20 \mathrm{sec}$ \\
\hline 4. De-ionized water rinse & $20 \mathrm{sec}$ \\
\hline 5. De-ionized water rinse & $20 \mathrm{sec}$ \\
\hline 6. Acetone rinse & $5-10 \mathrm{sec}$ \\
\hline 7. Dry with “warm wind" & Visual check \\
\hline 8. Run analysis & As soon as possible \\
\hline
\end{tabular}

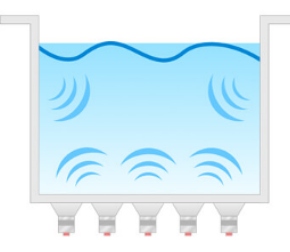

Soapy Water Ultrasonic bath $60 \mathrm{sec}$

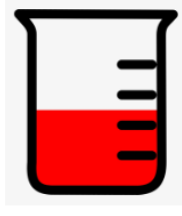

10\% Dilute Nitric Acid $90 \mathrm{sec}^{1}$

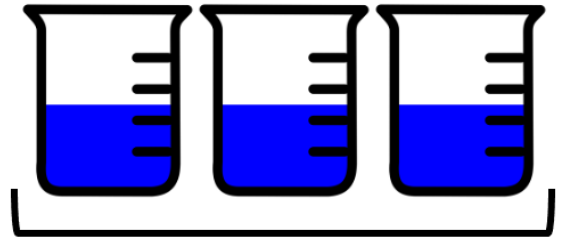

3-Step De-Ionized Water Rinse Cascade 20 sec each

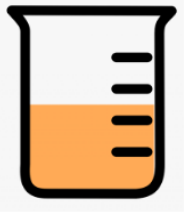

Acetone

Rinse 5-10 sec ${ }^{2}$

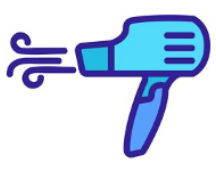

Dry with "Warm Wind" 3 


\section{Background}

In 1995-96, a GPP construction project paid for renovation of SM-66 G105 from a single, large, high-bay lab to a 2-story, multi-room characterization suite. While Sigma has a long history of metallurgical and physical characterization equipment, its chemical characterization capability needed to be upgraded and expanded. Following completion of the renovation, Sigma added or upgraded equipment for hydrogen, oxygen-nitrogen, GC/MS, particle/powder size, and carbonsulfur analyses. At the time, we had limited direct experience with some of these, particularly the elemental analyzers.

As part of this capability expansion, we purchased a Horiba EMIA-8200 Carbon/sulfur analyzer in late 1997. The equipment was installed at Sigma 1/27-2/2, 1998. Over the balance of that fiscal year, we ran 1000 samples through the analyzer to;

1) become proficient in the use and understanding of the equipment,

2) establish protocols for future measurements, and

3) perform analysis on samples for programmatic efforts.

During this time, most of the data were collected and reported to the individual programs being supported. We had intended to make a compilation report of our experiences and decisions, but that was never completed. This is an attempt to go back and catalog the history, report the protocols established, and present reasoning behind our decisions.

The three main protocols we established for uranium carbon analysis were;

1) standard and minimum sample sizes,

2) flux recipe, and

3) sample cleaning method.

Since monolithic solid samples were more easily available to us than they are today, we did not do adequate survey of sample morphology (solid, chips, powders) ${ }^{1}$ to evaluate potential variations in analysis results as a function of sample form. We suggest some investigation into this may be useful.

While this analytic equipment is capable of measuring sulfur in addition to the carbon, there was not a significant programmatic driver for us to measure sulfur as part of normal analysis and reporting. In many cases, sulfur results are recorded in the log book, but not reported or used in any meaningful way.

\footnotetext{
${ }^{1}$ There are some results in Horiba EMIA-8400 log book \#1, pages 8-9, 13-14, 93, that indicate evaluating chip samples. There is also one page of hand-written notes with results of cleaning and aging chips.
}

Los Alamos National Laboratory, Sigma Division 


\section{Sample Size}

- We established $1 \mathrm{~g}$ as the standard sample size for solid, monolithic samples of uranium and most other materials, based upon manufacturer's recommendations and several sample size studies.

- We established $0.5 \mathrm{~g}(500 \mathrm{mg})$ as the minimum sample size we felt provided consistent results, based upon several sample size studies.

There are five sample size studies recorded in the log book, three using uranium and two using steel, we used to establish and confirm the use of this sample size range. The results of each study show that there is significant departure from the average carbon value and expansion of the standard deviation with sample sizes below $400-500 \mathrm{mg}$. We present the results for each of the sample size studies below. We decided that we felt comfortable using $500 \mathrm{mg}$ or larger samples and established that as our lower limit.

Nearly all of the samples we used for uranium carbon analysis were cut from rods or pins that were machined from the initial feed stock. We found that $3 \mathrm{~mm}$ diameter was about the maximum size we could hand cut with snips, electrician's pliers, or small bolt cutters in the G105 hood. Some samples were also cut on a benchtop metallurgical saw in the foundry.

\section{Low-carbon Uranium (FSDrum-16)}

We used Feedstock Drum 16 (FSDrum-16) as a low-carbon depleted uranium reference material to verify low-carbon results. There are approximately 100 FSDrum-16 samples recorded overall in the log book. The consolidated value of all $1 \mathrm{~g}$ FSDrum-16 samples is

\begin{tabular}{|l|c|}
\hline FSDrum-16 (all 1g samples) & ppmC \\
\hline Average Carbon Value & 57.4 \\
\hline Standard Deviation & 17.9 \\
\hline
\end{tabular}

We also used FSDrum-16 for a sample size study. Generally, we would run 10 samples at each size for materials we had not measured previously and for which we had adequate material for all the samples. As we gained experience with and feel for some of the materials, or had limited material supply, we would sometimes reduce this to 4 or 5 .

\begin{tabular}{|c|c|c|}
\hline $\begin{array}{c}\text { FSDrum-16 Nominal } \\
\text { Sample Size }(\mathrm{mg})\end{array}$ & $\begin{array}{c}\text { Average Carbon } \\
(\mathrm{ppmC})\end{array}$ & StDev \\
\hline 1000 & 62.1 & 9.4 \\
\hline 500 & 47.2 & 21.0 \\
\hline 250 & 77.7 & 32.7 \\
\hline
\end{tabular}

\footnotetext{
2 Pages $38,41-42,46-48,50,52,138,151$ of Horiba EMIA-8400 log book \#1

Los Alamos National Laboratory, Sigma Division
} 
When we plotted these results (Figure 1), we saw that the $500 \mathrm{mg}$ sample average and deviation overlaid the overall FSDrum-16 average of $57.5 \mathrm{ppmC}$, but the $250 \mathrm{mg}$ sample data was significantly higher and wider than our overall values. All four sample sets discussed in this section using solid sample forms exhibit a similar trend.

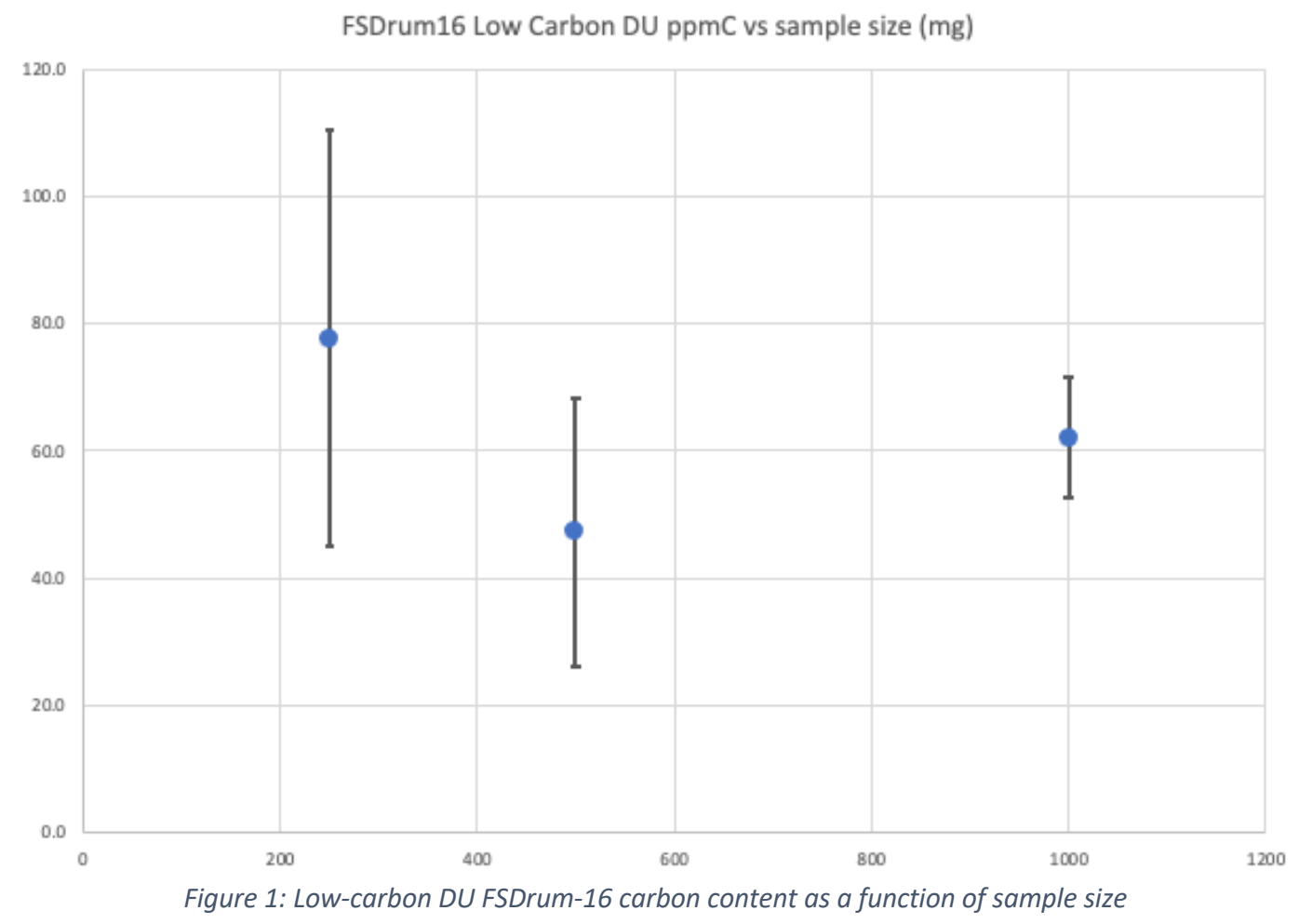

High-Carbon Uranium (98C-452)

We used samples from casting $98 \mathrm{C}-452^{3}$ to determine if there was any effect of high carbon level feedstock on the sample size study done on FSDrum-16. There were 10 samples run at each nominal mass.

\begin{tabular}{|c|c|c|}
\hline $\begin{array}{c}\text { 98C-452 Nominal } \\
\text { Sample Size }(\mathrm{mg})\end{array}$ & $\begin{array}{c}\text { Average Carbon } \\
(\mathrm{ppmC})\end{array}$ & StDev \\
\hline 1000 & 304.1 & 21.1 \\
\hline 500 & 307.7 & 102.7 \\
\hline 250 & 377.8 & 82.2 \\
\hline 100 & 433.5 & 26.0 \\
\hline
\end{tabular}

${ }^{3}$ Pages 145-146

Los Alamos National Laboratory, Sigma Division 
We can see that these results show a pattern similar(Figure 2) to the low-carbon uranium results of a shift in average values and some expansion of the standard deviation.

\section{C-452 DU ppmC vs Sample Mass (mg)}

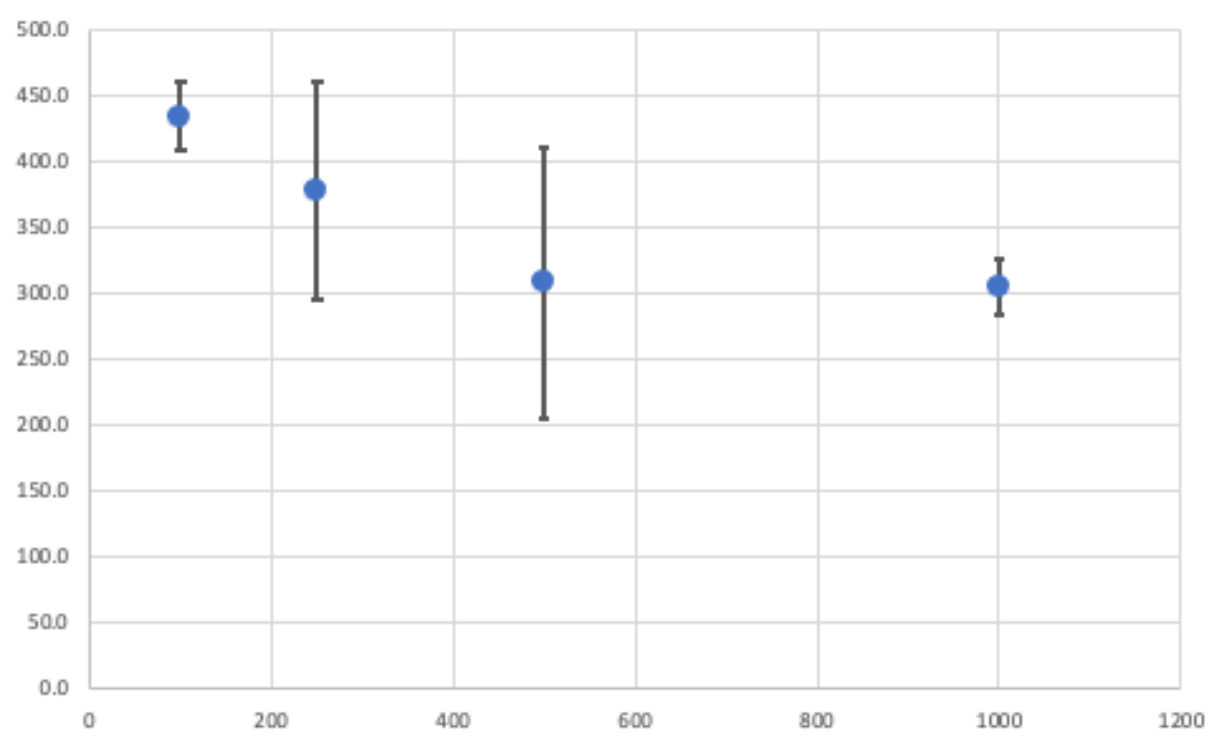

Figure 2: High-carbon DU 98C-452 carbon content as a function of sample size

\section{Natural Uranium Round Robin}

As part of a DOE-wide effort to understand uranium carbon analysis, Lawrence Livermore led a carbon analysis round robin using natural uranium rods as the feedstock. Our recollection is that a number of rods were gang cast and distributed to LLNL, LANL, Y-12, MSC ${ }^{4}$, AeroJet ${ }^{5}$, and perhaps StarMet ${ }^{6}$ for carbon analysis. Los Alamos received rods A3, B1, C15, E11, D13, and F9. ${ }^{7}$ We were unable to locate any final reports from the round robin study. This is the most extensive sample size study we performed on uranium.

\begin{tabular}{|c|c|c|}
\hline $\begin{array}{c}\text { Natural Uranium Round } \\
\text { Robin Lots }\end{array}$ & $\begin{array}{c}\text { Average Carbon } \\
\text { (ppmC) }\end{array}$ & StDev \\
\hline RR-A3 & 56.9 & 3.0 \\
\hline RR-B1 & 45.5 & 17.1 \\
\hline RR-C15 & 56.5 & 6.1 \\
\hline RR-D13 & 47.9 & 12.6 \\
\hline RR-E11 & 103.9 & 32.6 \\
\hline RR-F9 & 53.5 & 17.0 \\
\hline
\end{tabular}

\footnotetext{
${ }^{4}$ Manufacturing Sciences Corporation in Oak Ridge TN

${ }^{5}$ AeroJet (now AeroJet Rocketdyne) maintains uranium fabrication facilities outside Jonesborough TN

${ }^{6}$ Carolina Metals, subsequently purchased by StarMet, operated a uranium conversion facility outside Barnwell SC

${ }^{7}$ Pages 112-118

Los Alamos National Laboratory, Sigma Division
} 
We performed sample size evaluations of two lots from the round robin material, D13 and F9. Lot F9 shows results very similar to FSDrum-16 and 98C-452. The $500 \mathrm{mg}$ samples have a very similar average, the average value of the $100 \mathrm{mg}$ samples is higher than the larger sample sizes and has a larger standard deviation.

\begin{tabular}{|c|c|c|}
\hline $\begin{array}{c}\text { RR-F9 Nominal Sample } \\
\text { size }(\mathrm{mg})\end{array}$ & $\begin{array}{c}\text { Average Carbon } \\
\text { (ppmC) }\end{array}$ & StDev \\
\hline $1000^{8}$ & 53.5 & 17.0 \\
\hline $500^{9}$ & 47.5 & 17.4 \\
\hline $100^{10}$ & 76.0 & 31.1 \\
\hline
\end{tabular}

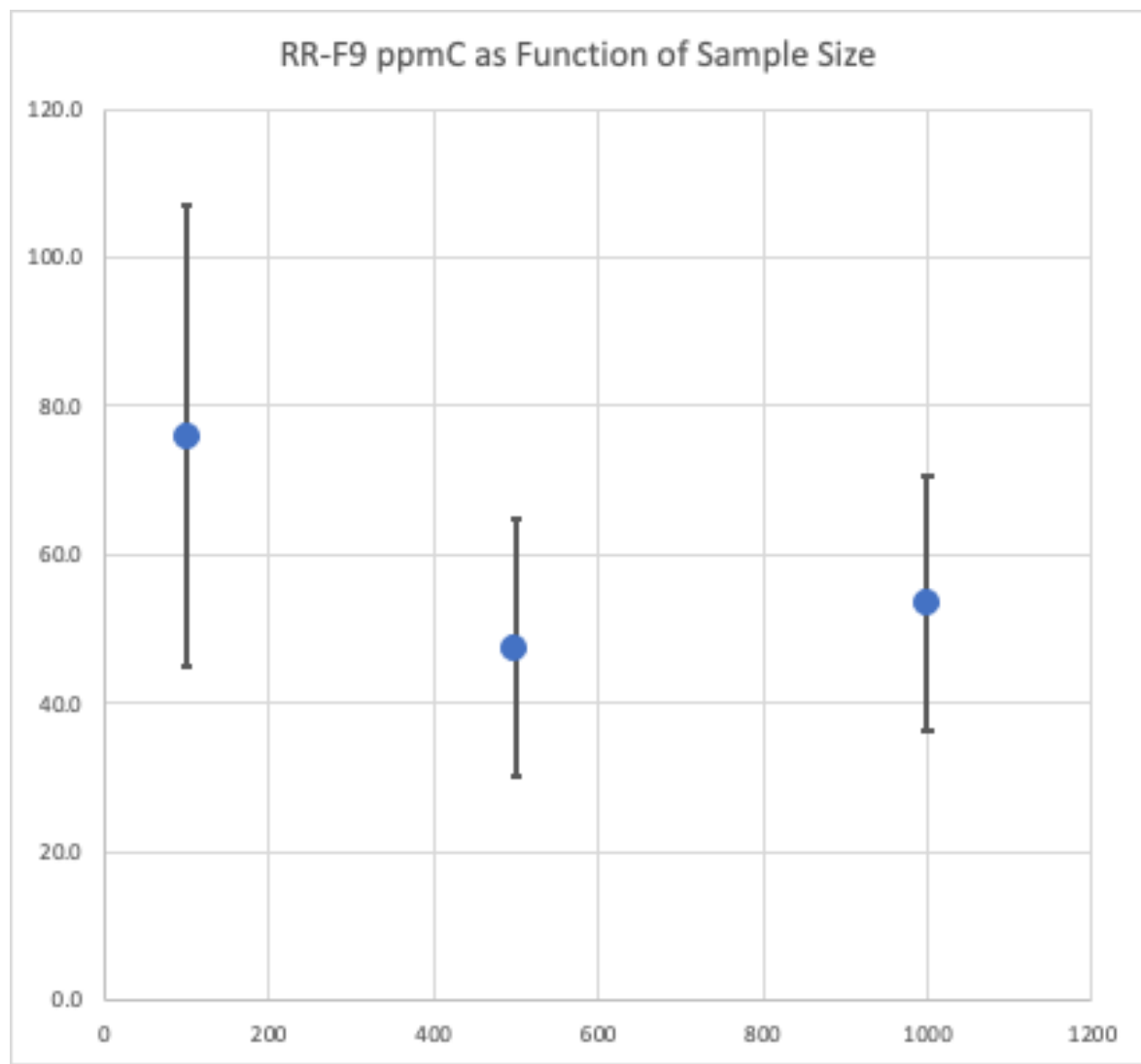

Figure 3: Natural Uranium Round Robin Lot F9 carbon content as a function of sample size

8 Pages $113-114$

${ }^{9}$ Page 114

${ }^{10}$ Pages $114-115$

Los Alamos National Laboratory, Sigma Division 
We added a variable into the sample size study of Lot D13. In addition to repeating the sample sizes we had previously used, we tried a "light flux" mix with the $100 \mathrm{mg}$ notional samples. We reduced the flux amounts to

\section{$0.5 g \mathrm{~W}+0.1 \mathrm{~g} \mathrm{Sn}+100 \mathrm{mg}$ sample}

in an attempt to have the flux:sample ratio more closely match the notional $1 \mathrm{~g}$ tests. We were surprised to find that the "light flux" seemed to bring the averages back closer in line with the $1 \mathrm{~g}$ sample results, but still not all the way.

\begin{tabular}{|c|c|c|}
\hline $\begin{array}{c}\text { RR-D13 Nominal Sample } \\
\text { size (mg) }\end{array}$ & $\begin{array}{c}\text { Average Carbon } \\
\text { (ppmC) }\end{array}$ & StDev \\
\hline $1000^{11}$ & 47.9 & 12.6 \\
\hline $250^{12}$ & 69.1 & 11.5 \\
\hline 100 Standard Flux $^{13}$ & 103.9 & 32.6 \\
\hline 100 "Light Flux" $^{14}$ & 72.5 & 48.6 \\
\hline
\end{tabular}

\footnotetext{
${ }^{11}$ Page 112

12 Pages $115-116$

13 Page 116

${ }^{14}$ Pages $117-118$
}

Los Alamos National Laboratory, Sigma Division 


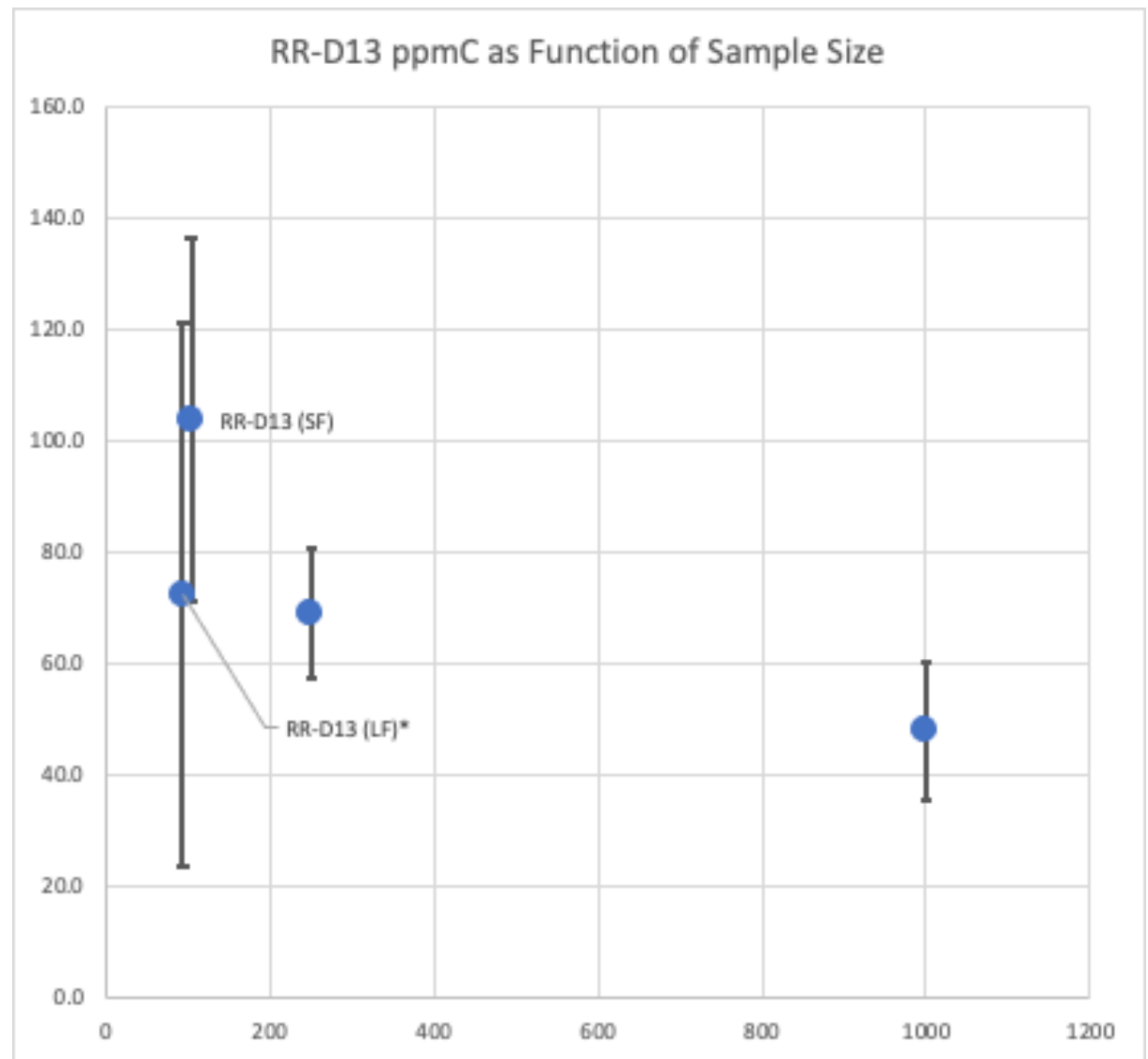

Figure 4: Natural Uranium Round Robin Lot D13 carbon content as a function of sample size. SF $=$ Standard Flux. LF = Light Flux

\section{Unknown Steel Rod}

More than a year after the main efforts on sample size, we apparently revisited the topic with a steel rod sample of unknown origin and carbon level. For the smaller samples, we again used the same "light flux" recipe described in the round robin analysis.

\begin{tabular}{|c|c|c|}
\hline $\begin{array}{c}\text { Steel Rod Nominal } \\
\text { Sample size (mg) }\end{array}$ & $\begin{array}{c}\text { Average Carbon } \\
\text { (ppmC) }\end{array}$ & StDev \\
\hline $1000^{15}$ & 348.3 & 7.0 \\
\hline $500^{16}$ & 357.5 & 7.3 \\
\hline $250^{\text {"Light Flux" 17 }}$ & 343.5 & 12.0 \\
\hline $100^{\text {"Light Flux" 18 }}$ & 330.3 & 12.1 \\
\hline
\end{tabular}

\footnotetext{
${ }^{15}$ Pages $128-129$

${ }_{16}$ Pages $129-130$

${ }^{17}$ Page 130

${ }_{18}$ Pages 130-131
}

Los Alamos National Laboratory, Sigma Division 


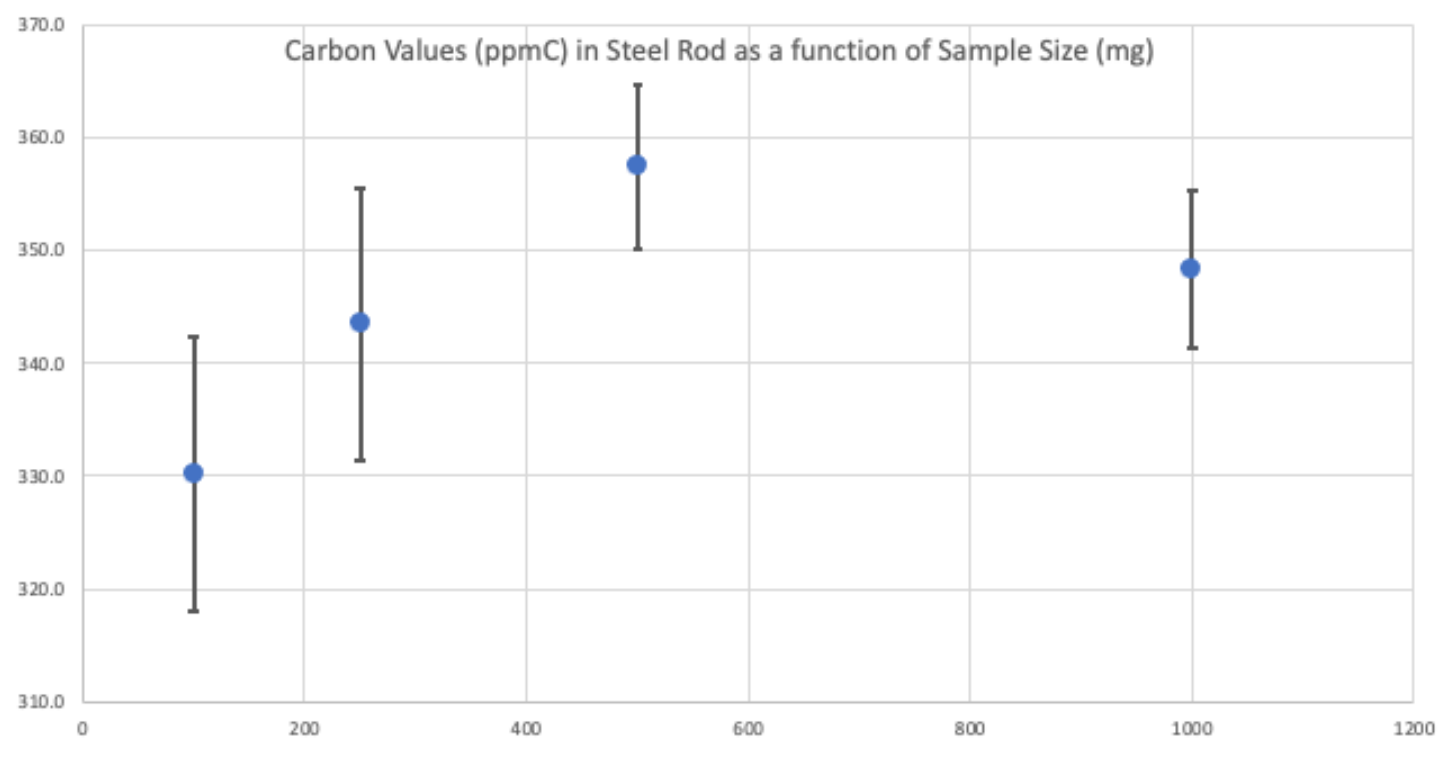

Figure 5: Unknown steel rod carbon content as a function of sample size

One interesting observation in this data set is that similar to the round robin samples, the light flux seems to reduce the measured value of carbon at lower sample sizes rather than raise it as seen in the previous uranium samples.

\section{Granular Steel Standard}

Not long after the steel rod analysis, we performed a sample size study using a commercial 370 ppmC granular steel standard. ${ }^{19}$

In the first series, we used the standard flux recipe throughout the range of masses. Since the granular material was very easy to weigh, we were able to perform tests at more tightly spaced mass values. Previously we had seen that at some sample mass value, there is a deviation from the $1 \mathrm{~g}$ sample average, and we were interested to see if we could determine a value for the breakover point that could help confirm our 500mg sample minimum protocol. Four samples at each mass were analyzed.

\begin{tabular}{|c|c|c|}
\hline $\begin{array}{c}\text { 370ppmC granular steel } \\
\text { standard-standard flux- } \\
\text { Nominal Sample Size } \\
(\mathrm{mg})\end{array}$ & $\begin{array}{c}\text { Average Carbon } \\
\text { (ppmC) }\end{array}$ & StDev \\
\hline 1000 & 356.1 & 2.0 \\
\hline 750 & 363.6 & 4.6 \\
\hline 500 & 378.2 & 8.0 \\
\hline
\end{tabular}

${ }^{19}$ Pages 139-140

Los Alamos National Laboratory, Sigma Division 


\begin{tabular}{|c|c|c|}
\hline 400 & 388.8 & 6.8 \\
\hline 300 & 402.6 & 12.7 \\
\hline 200 & 431.5 & 15.0 \\
\hline 100 & 505.0 & 37.1 \\
\hline 50 & 579.6 & 22.7 \\
\hline
\end{tabular}

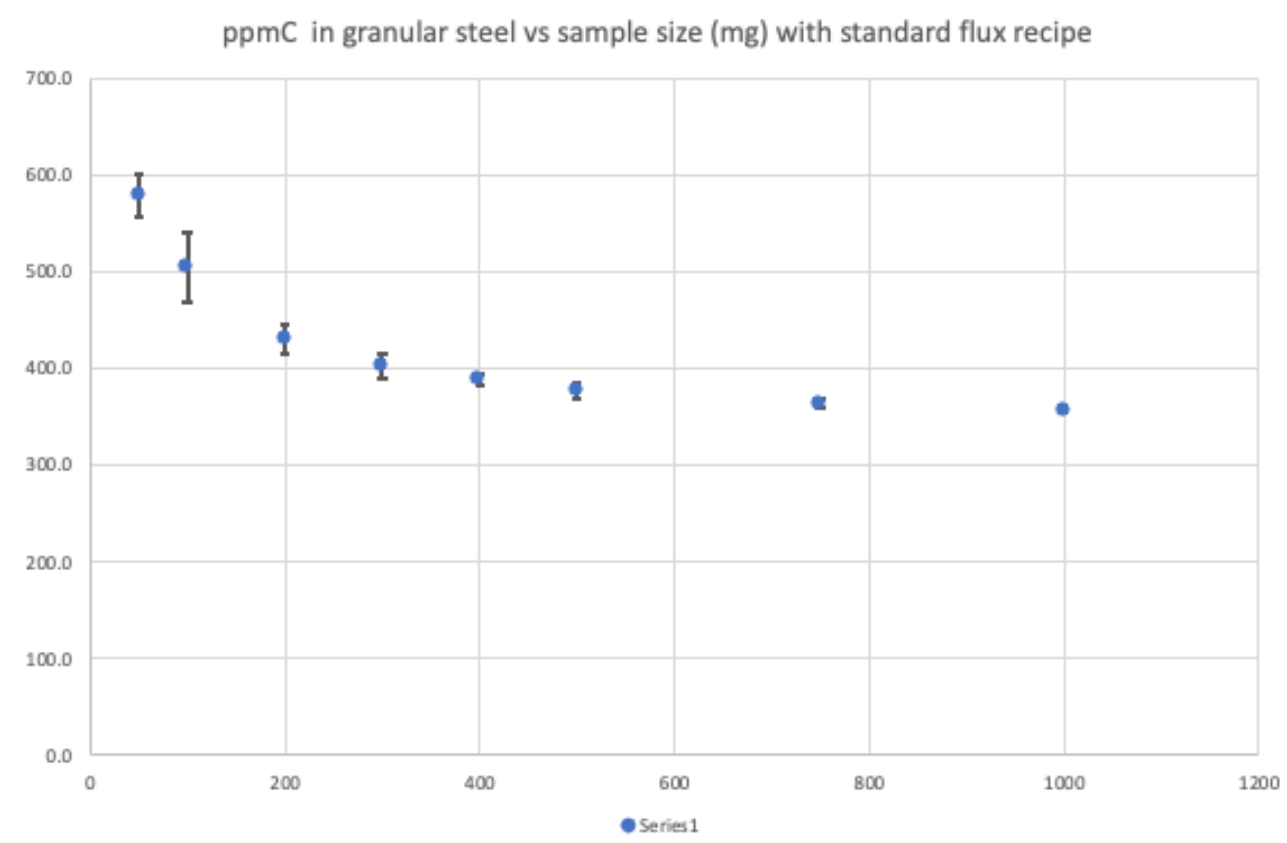

Figure 6: Commercial 370ppmC granular steel standard w/standard flux carbon content as a function of sample size

It appears once again, that there is a sample size effect on the results. The data suggest a deviation point somewhere between 400-500mg sample size.

Based upon the results with previous "light flux" analyses, we decided to perform the same sample size levels. As before, four samples were run for each mass.

\begin{tabular}{|c|c|c|}
\hline $\begin{array}{c}\text { 370ppmC granular steel } \\
\text { standard-“light” flux- } \\
\text { Nominal Sample Size (mg) }\end{array}$ & $\begin{array}{c}\text { Average Carbon } \\
\text { (ppmC) }\end{array}$ & StDev \\
\hline 1000 & 343.1 & 1.9 \\
\hline 500 & 355.6 & 7.2 \\
\hline 400 & 357.4 & 4.8 \\
\hline 300 & 345.7 & 12.1 \\
\hline 200 & 328.4 & 20.8 \\
\hline 100 & 300.0 & 12.5 \\
\hline 50 & 174.2 & 29.7 \\
\hline
\end{tabular}




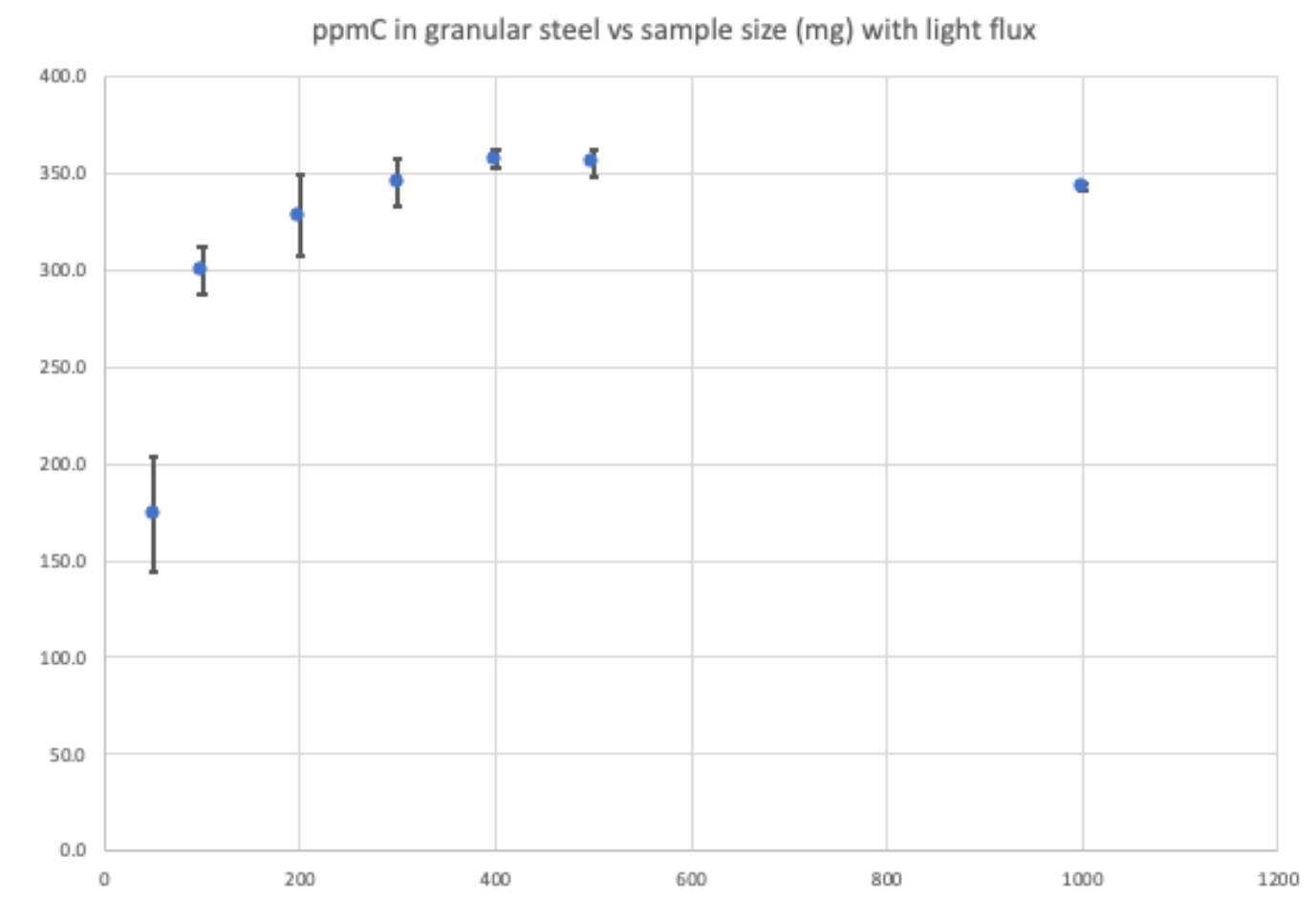

Figure 7: Commercial 370ppmC granular steel standard w/"light flux" carbon content as a function of sample size

With the "light flux," there appears to be a similar break point in the data that appears at approximately the same sample size $(400-500 \mathrm{mg}$ ) as the standard flux samples. What is curious is that with the "light flux" the deviation is in the opposite direction for all of the sample sets. We did not perform any additional tests to evaluate this result and leave it to future investigators to interrogate if desired.

The overall feeling at the end of all these studies was that our initial 500mg sample size was likely an appropriate minimum for consistent results from monolithic solid uranium samples.

\section{Additional Data Sets Not Used}

There was a sixth sample size study using $1 \mathrm{~g}$ commercial $187 \mathrm{ppmC}$ steel pin standards cut in half (500mg nominal samples) and in thirds (333mg nominal samples) ${ }^{20}$. It is not clear that all these tests were performed with the same protocols and to the same rigor we had been using for the five sample size campaigns detailed above. We have chosen not to include them in this report.

\footnotetext{
${ }^{20}$ Pages 53-54, 54, 56-57, 57-58, 59-60
}

Los Alamos National Laboratory, Sigma Division 
Flux

- We established the following flux recipe standard based upon the manufacturer's operating manual and some experimental testing.

\section{$1.5 \mathrm{~g} \mathrm{~W}$ (tungsten) $+0.3 \mathrm{~g} \mathrm{Sn}($ tin) + sample}

A fluxing agent (accelerant) is usually used to ensure complete melting and combustion of the sample. We retained the flux recipe and layering provided in the manufacturer's instruction manual for most of the samples we tested.

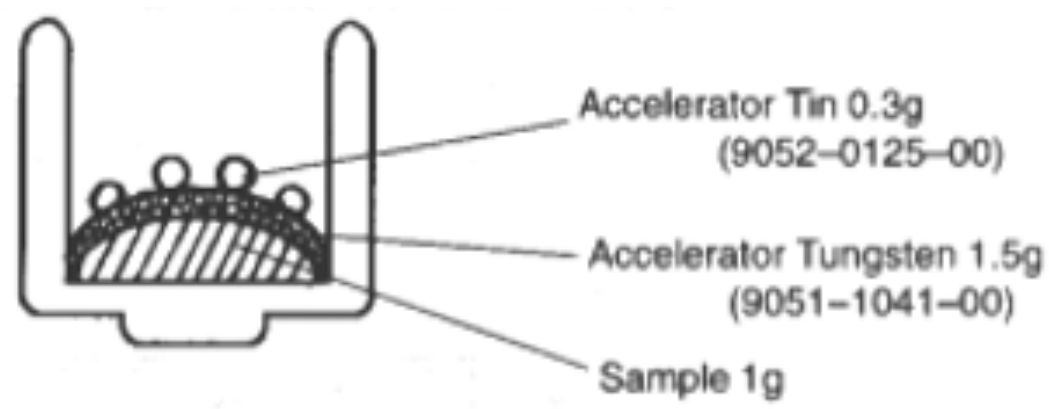

Figure 8: Flux recipe recommended in Horiba Instruction Manual 21

We evaluated using a heavy flux load

$$
2.0 g W+0.5 g S n+1 g \text { sample }
$$

but found this caused unacceptable crucible boil-over and splattering on the inside of the furnace tube. We declined to use this mixture for any other samples.

We also tried using a "light flux" recipe, especially for smaller ( $<500 \mathrm{mg})$ samples.

$$
0.5 g \text { W }+0.1 g S n+\text { sample }
$$

The results of these tests are detailed above. We generally did not use the "light flux" on any programmatic samples since we nearly always were able to analyze sample masses close to $1 \mathrm{~g}$.

\footnotetext{
${ }^{21}$ Image taken from Horiba EMIA-8200W Instruction Manual, Second Edition, Horiba LTD, December 1997, Code 1042935100, Page 51
}

Los Alamos National Laboratory, Sigma Division 


\section{Sample Preparation}

- We established the following sample preparation method based upon manufacturer's recommendations, experience at other facilities performing uranium carbon analysis, and our own evaluation tests. ${ }^{22}$

\begin{tabular}{|l|l|}
\hline 1. Ultrasonic bath in soapy water & $60 \mathrm{sec}$ \\
\hline 2. $10 \%$ dilute nitric acid & $90 \mathrm{sec}$ \\
\hline 3. De-ionized water rinse & $20 \mathrm{sec}$ \\
\hline 4. De-ionized water rinse & $20 \mathrm{sec}$ \\
\hline 5. De-ionized water rinse & $20 \mathrm{sec}$ \\
\hline 6. Acetone rinse & $5-10 \mathrm{sec}$ \\
\hline 7. Dry with "warm wind" & Visual check \\
\hline 8. Run analysis & As soon as possible \\
\hline
\end{tabular}

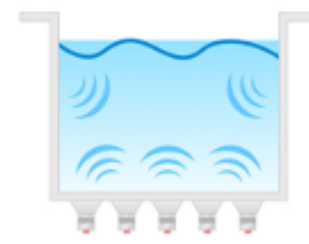

Soapy Water
Ultrasonic bath $60 \mathrm{sec}$
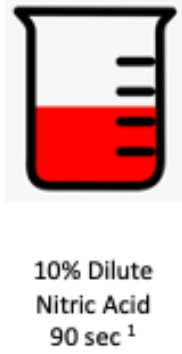

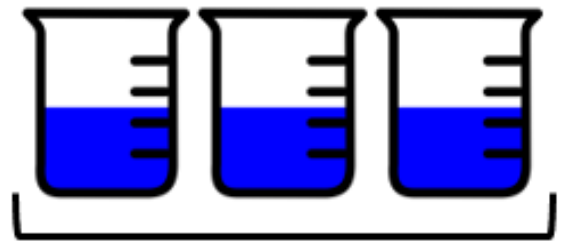

3-Step De-lonized Water Rinse Cascade 20 sec each

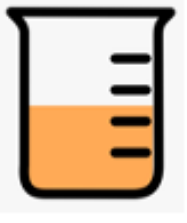

Acetone

Rinse $5-10 \sec ^{2}$

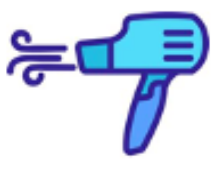

Dry with "Warm Wind" 3

As with any chemical analysis, sample preparation is important to ensure no unintended carbon-containing material is analyzed and to remove any contaminants from the sample surface that might affect analytic results. This particular subject caused the most discussion within the DOE carbon analysis community.

During installation, the Horiba technician suggested that we use a dilute acid etch, a water rinse, and acetone or ethanol for drying. Since acetone contains carbon, the DOE community questioned whether or not the final drying rinse affected our carbon results. We used both a steel standard ${ }^{23}$ and FSDrum-16 uranium samples to evaluate the effect of various cleaning, rinsing, and drying methods.

\footnotetext{
22 In the image,

Note 1: A 5:1 Concentrated Nitric Acid cleaning for 15-20 seconds was also used on occasion

Note 2: If fully dried/evaporated from the sample surface, acetone was shown not to affect the carbon results Note 3: This term was taken from one of the Horiba EMIA manuals. We utilized a standard commercial electric heat gun to dry the samples

${ }^{23}$ LECO catalog item 502-064 C in steel pin standard. 187ppmC +/- 7ppmC
}

Los Alamos National Laboratory, Sigma Division 


\begin{tabular}{|l|c|c|}
\hline Sample Condition & $\begin{array}{c}\text { Average Carbon } \\
\text { (ppmC) }\end{array}$ & StDev \\
\hline Steel Pin Standard - as declared by LECO & 187 & 7 \\
\hline Pin Standard - no cleaning 24 & 179.0 & 3.8 \\
\hline $\begin{array}{l}\text { pin standard Concentrated Nitric Acid clean (90 second } \\
\text { soak) + 3-step De-lonized water cascade rinse 25 }\end{array}$ & 163.6 & 5.0 \\
\hline $\begin{array}{l}\text { pin standard 10\% dilute Nitric Acid clean (90 second } \\
\text { soak) + 3-step De-lonized water cascade rinse 26 }\end{array}$ & 194.5 & 5.0 \\
\hline $\begin{array}{l}\text { pin standard with no acid clean, instead used simple 3- } \\
\text { step De-lonized water cascade rinse 27 }\end{array}$ & 192.4 & 3.5 \\
\hline & & \\
\hline $\begin{array}{l}\text { pin standard with no acid clean or water rinse, instead } \\
\text { cleaned with 5-10 second dip in acetone 28 }\end{array}$ & 194.8 & 1.8 \\
\hline $\begin{array}{l}\text { pin standard with no acid clean or water rinse, instead } \\
\text { with long soak in acetone } 29\end{array}$ & 191.2 & \\
\hline & & \\
\hline $\begin{array}{l}\text { pin standard with no acid clean or water rinse, instead } \\
\text { with 10 second dip in ethanol }\end{array}$ & 191.1 & 3.0 \\
\hline & & \\
\hline $\begin{array}{l}\text { pin standard soaked in Trimsol (water soluble cutting } \\
\text { oil used in DU machining) with no rinse. Some visual } \\
\text { residual Trimsol could be seen on sample 31 }\end{array}$ & 257.5 & 34.0 \\
\hline $\begin{array}{l}\text { pin standard soaked in Trimsol (water soluble cutting } \\
\text { oil used in DU machining) rinsed in an ultrasonic water } \\
\text { bath 32 }\end{array}$ & & \\
\hline
\end{tabular}

Based on the results above, we felt comfortable the final acetone rinse did not affect the carbon results. Even with a short dip or a long soak in acetone, the carbon results are in line with the carbon levels of the certified standard. We believe that effectively no carbon remains on the surface of the sample after the acetone evaporated.

On the other hand, the need for appropriate cleaning is evident from the results of samples with residual cutting oils on the surface. This did not come as a surprise to us.

\footnotetext{
24 Page 26

25 Pages 26-27

26 Page 28

27 Page 29

28 Page 30

29 Page 31

30 Pages 31-32

31 Page 32

32 Page 33
}

Los Alamos National Laboratory, Sigma Division 
While acetone did not appear to affect the results on steel pins, we wanted to test the same method with uranium samples.

\begin{tabular}{|l|c|c|}
\hline Sample Condition & $\begin{array}{c}\text { Average Carbon } \\
\text { (ppmC) }\end{array}$ & StDev \\
\hline FSDrum-16 consolidated results & 57.4 & 17.9 \\
\hline $\begin{array}{l}\text { FSDrum16 1g samples, 10\% dilute nitric acid clean (90 } \\
\text { seconds) with 3-step De-lonized water rinse (no } \\
\text { acetone rinse) }\end{array}$ & & \\
\hline $\begin{array}{l}\text { FSDrum16 1g samples, 10\% dilute nitric acid clean (90 } \\
\text { seconds) with 3-step De-lonized water rinse, with } \\
\text { acetone rinse }\end{array}$ & 59.7 & 17.0 \\
\hline
\end{tabular}

As with the steel, it does not appear that a final acetone drying rinse affects carbon results in uranium. The DOE carbon analysis community concurred with our conclusion.

We did try some other sample preparation methods ${ }^{35}$ but did not see any analytic benefit or other advantage over the fairly straightforward acid-rinse cascade protocol described here.

\section{Sample Morphology}

Since monolithic solid samples were more easily available to us 20 years ago than they are today, we did little to evaluate the effect of sample morphology on carbon analysis results. There was concern at the time about how the increase in surface area and the challenge of adequately cleaning chip samples might impact repeatability and reliability of the measurements versus solid samples. There are a few places in the log book that indicate chip samples ${ }^{36}$ were analyzed, and there is also one page of hand-written notes with results of cleaning and aging chips. Upon reflection, it is not clear that these results are adequately systematic or understood today at a level to provide insight or guidance to future analyses.

We suggest some investigation into sample morphology would likely be useful. We also think it may be useful to consider and evaluate using smaller flux:sample ratios if chip samples are significantly lower mass than the protocols we established herein.

\footnotetext{
${ }^{33}$ Pages 38, 42

${ }^{34}$ Pages 38,42

${ }^{35}$ Including a 5V, 5sec, phosphoric acid electropolish, Page 39

${ }^{36}$ Pages 8-9, 13-14, 93, these runs may have been focused more on cleaning than accuracy

Los Alamos National Laboratory, Sigma Division
} 